\title{
SANTIAGO DE COMPOSTELA EN LA CRISIS DEL CAMBIO DE SIGLO (1699-1716). A PROPÓSITO DE UN BARROCO APORTUGUESADO ${ }^{1}$
}

Data recepción: 2011/05/15

Data aceptación: 2011/07/01

Contacto autor: ivan.rega@hahs.udl.cat
Iván Rega Castro

Universitat de Lleida

\section{RESUMEN}

Está claro que toda crisis en el "sistema del arte", si está bien controlada, es un signo de vitalidad, antes que de agotamiento; de este modo, crisis puede identificarse simplemente con "cambio". ¿Cuáles son entonces las condiciones que generan una situación de este tipo? En Santiago de Compostela alrededor de 1700, especialmente en el campo de la talla dorada y la retablística, se produjo un punto de inflexión en el "campo de producción" y un cambio de repertorio, promovido por los más dinámicos círculos artísticos y religiosos, capitaneados por Domingo de Andrade; una situación que está relacionada con la llegada a Santiago de Compostela de entalladores y escultores — José y Ciprián Domínguez Bugarín, Francisco de Castro Canseco- del sur de Galicia. Tal vez estos desarrollos del arte de la talla y la retablística hayan sido la manifestación de un nuevo "gusto" o sensibilidad estética que conocemos como "barroco aportuguesado".

Palabras clave: Arte barroco en Galicia, Santiago de Compostela, talla dorada y retablística barroca, Domingo de Andrade, José y Ciprián Domínguez Bugarín, Francisco de Castro Canseco

\begin{abstract}
It is clear that crises in a "the system of art", if they can be well-controlled by the system, are signs of vitality, rather than exhaustion. Therefore, crisis should be identified simply with "change". What then are the conditions which give rise to a situation of this kind? In Santiago de Compostela in the 1700s, particularly in the field of the gilt woodwork and baroque retables, there was a turning point in the "field of production" and a change of repertoire, promoted by the most dynamic artistic and religious circles, led by Domingo de Andrade; a situation that correlates with the arrival to Santiago de Compostela of woodcarving sculptors — José y Ciprián Domínguez Bugarín, Francisco de Castro Canseco - from southern Galicia. Perhaps this wood carving and retables's developments have been the manifestation of a new "taste" or aesthetic sensibility we know as the Baroque "aportuguesado".
\end{abstract}

Keywords: Baroque art in Galicia, Santiago de Compostela, gilt woodcarving and baroque retables, Domingo de Andrade, José and Ciprián Domínguez Bugarín, Francisco de Castro Canseco

Todo apunta a la conclusión de que la locución "el lenguaje del arte" es más que una metáfora $[\ldots]^{2}$

E. Gombrich, 1977
En 1665, se hacían, o por mejor decir, "tallaban" en Madrid, con destino a la envoltura y adorno de la capilla mayor de la Catedral y «[...] por los mejores maestros de la Corte, cartochas [¿cartones?, ¿cartelas?], tarjetas y festones»; es decir, lle- gaba en estas fechas a Compostela el adorno base del "lenguaje" barroco - como se sabe, tarjetas, festones, cartones y florones definen el estilo de Pedro de la Torre (fall. 1677) y, a partir de 1665, también el de Domingo de Andrade 3 . 
Hay que esperar, pues, al fin de siglo para dar inicio a un cambio de "código".

Domingo de Andrade (fall. 1712) siguió trabajando en la Catedral hasta 1710. No obstante, el siglo XVIII, en Santiago de Compostela, se inauguraba con la llegada de nuevos lenguajes y artistas "foráneos", en su mayoría procedentes del sur de Galicia; caso de José Domínguez Bugarín y Domingo Rodríguez de Pazos. Éste último ${ }^{4}$ —titulado "maestro de arquitectura, tallista y ensamblador"-, cuando hizo ajuste del retablo mayor de San Bieito do Campo (Santiago de Compostela), el 12 de marzo de 1701, dio palabra de que «[...] la talla de la obra había de ser de escarola al modo de la que se fabrica para el convento de Santa Clara [donde trabajaba el retablero Domínguez Bugarín, desde julio de 1700]» ${ }^{5}$. Es cierto que estas «[...] nuevas modas en el mobiliario litúrgico, son, seguramente, las que originan el deseo de sustituir los antiguos retablos, en torno a los principios del siglo XVIII» ${ }^{6}$; y desde luego, es en este tiempo cuando la retablística de la Galicia atlántica, al igual que en las Castillas, se "revoluciona", caracterizada por su eclecticismo y complejidad en la decoración, reflejando, en cierto modo, el gusto por un estilo naturalista y por lo "pintoresco".

Sin embargo, el "acostumbrado" adorno de hojarasca de acanto y querubines no lo era todo: el 25 de diciembre de 1735, cuando el fabriquero de la Catedral y el escultor Andrés Ignacio Mariño ajustaron la obra del retablo de la Sala Capitular, se dictó y se le obligó a «[...] hacer toda la dicha talla espinacas contadas y obalos [...] y la talla ha de ser de la moda mas primorosa y loable que pueda hacer el mas discreto y curioso artifice [en éstas y en las citas siguientes, las cursivas son mías]» ${ }^{7}$.

Demasiada verdura; con razón en la "Scriptura de la obra de reparos que se han de hazer en el retablo de la yglesia del convento de Santa Clara" (Pontevedra), el 20 de julio de 1734, «[...] dijeron que [...] el Retablo de el Altar mayor de la yglesia del citado Convento [... . esta faltoso de algunos reparos según el Arte de Agricultura [sic] que profesan los dichos Antonio y Gaspar Dacanle $[. ..] »^{8}$. Este lapsus calami del escribano público, confundiendo agricultura y arquitectura,

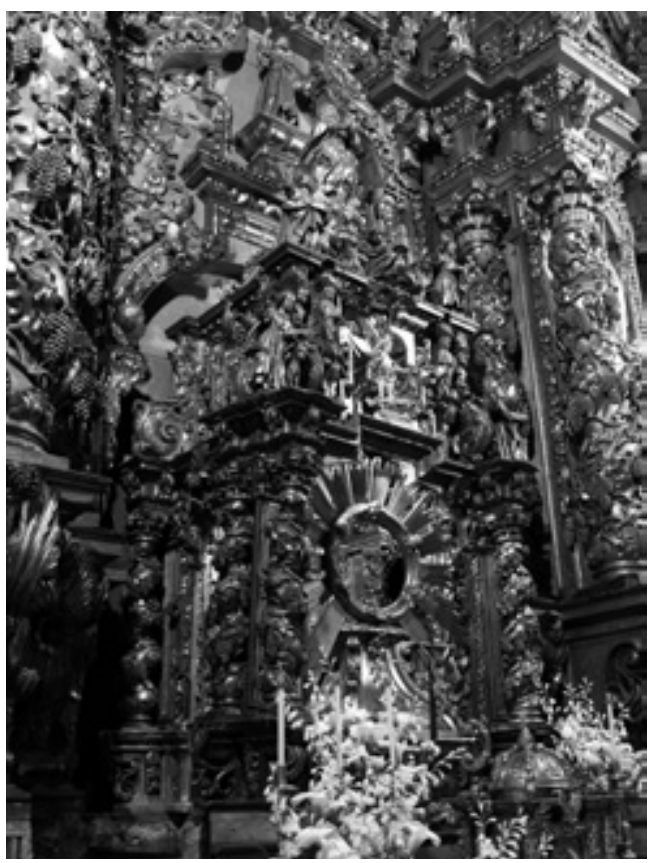

Fig. 1. ¿José y Ciprián Domínguez Bugarín?, cuerpo bajo del retablo mayor del convento de Santa Clara (Santiago de Compostela), 1700-1701.

habla bien a las claras del arte de tallistas, carpinteros-labrantes, escultores y retableros.

\section{El estilo, la moda, el gusto}

La moda se distingue de la norma por el hecho de que regula el sistema orientándolo no hacia cualquier constancia, sino hacia la variabilidad [al cambio]. Al mismo tiempo, la moda aspira cada vez a devenir norma $[\ldots]^{9}$

J. M. Lotman y B. A. Uspenskij, 1971

El 14 de julio de 1700 —una fecha capital en la historia del retablo gallego- las monjas de Santa Clara adjudicaban el retablo mayor de su iglesia a José Domínguez Bugarín; comprometiéndose éste a hacerlo en apenas trece meses y de acuerdo a la «[...] planta echa por don Domingo de Andrade $»^{10}$ (Fig. 1). Era condi- 


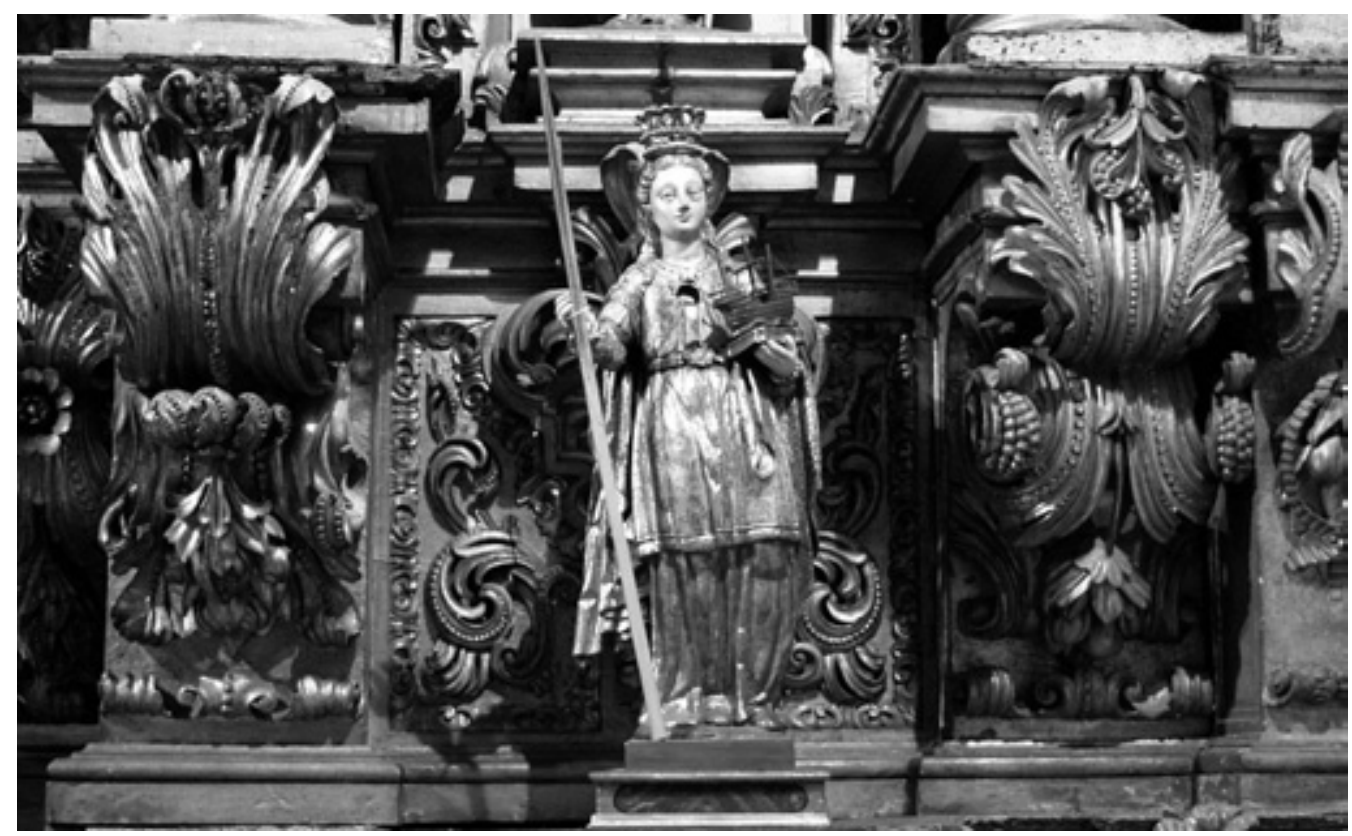

Fig. 2. ¿José y Ciprián Domínguez Bugarín?, retablo mayor del convento de Santa Clara, 1700-1701. Detalle de la Predela y talla de "escarola".

ción fabricarlo en Santiago, dentro de la iglesia del convento; esto, quizá hizo "explosionar" los repertorios ${ }^{11} \mathrm{y}$, en seguida, se sintieron sus efectos en el aparato de producción. Anteriormente, José Domínguez Bugarín regentó tienda y taller en Tui al menos hasta marzo de 1699'2; luego se fue al norte. Quizá se trajera consigo algún familiar para ayudarle en el trabajo de carpintería y talla: tal vez Ciprián Domínguez Bugarín era su hermano ${ }^{13}$, tal vez su hijo, pero no hay duda que éste se formó junto a José 14 . De hecho, se sospecha que trabajaron juntos ya para las clarisas de Santiago y, años después, es más que probable que madurase a la sombra de Domingo de Andrade en el obradoiro de la Catedral de 1707 a $1708^{15}$.

Tras la muerte de Bernardo Cabrera (fall. 1663) y Mateo de Prado (fall. 1677), ciertamente se asistía en Santiago de Compostela a una carestía de mano de obra "cualificada", en los talleres de escultura y talla. De tal forma que ninguno de los escultores de la Ciudad Santa acaba de descollar y convertirse en "dominante". Esto quiso solucionarse al traerse entalladores y retableros desde el sur ${ }^{16}$ : José y Ciprián Domínguez Bugarín (1700), originarios de Tui; Domingo Rodríguez de Pazos (1701) también desde a raia, natural de San Xoán de Fornelos (Salvaterra de Miño, Pontevedra), y, en especial, Francisco de Castro Canseco (1714), Ilegado de Ourense.

Como se dijo antes, en marzo de 1701 se ajustaba el retablo mayor de San Bieito do Campo con el "Maestro de Fornelos"; tal vez "socio" de Miguel de Romay —antes que su discípulo, como aventuró Fernández Álvarez-, ya que éste actuó como su fiador ${ }^{17}$. En esta ocasión, tenía que seguir la planta que le dieron el rector, D. Nicolás de Ulloa Ribadeneira, y su fabriquero; $y$, desde luego, se insistió en que éste 
debía «[...] ocupar toda la capilla mayor, con columnas salomónicas y racimos de parra»; además

[...] las cuatro columnas principales del primer cuerpo tendrían doce cuartas y media y el arco de arriba en que termina la obra aplefonado [casetones con florones] a imitación del de la capilla de Doña María de Calo, de Salomé [esto es, la de Santa Teresa del lado del evangelio, inclusa en la iglesia de Santa María Salomé (Santiago de Compostela); ¿obra de Pedro de Taboada?, después de 1670]. Toda la talla de la obra había de ser de escarola al modo de la que se fabrica para el convento de Santa Clara ${ }^{18}$.

Siendo así, a falta de ensamblar y asentar el altar mayor de las clarisas — dado que aún restaban unos seis meses para su término-, el taller de José Domínguez Bugarín, dentro de la cerca del convento, ya dejaba sentir su influjo en Santiago de Compostela. Si bien, es posible que Rodríguez de Pazos se topara con los "usos artísticos" compostelanos y, más en concreto, de los Domínguez Bugarín; trabajando junto a éstos, poco antes, en los retablos de la iglesia de las clarisas (ca. 1700-1704) ${ }^{19}$. Lo cierto es que este estilo triunfó en seguida en el aparato de producción, justamente merced a las hojas de "escarola" venidas de la diócesis de Tui y a una talla "al modo de la que se fabrica para el convento de Santa Clara" (Fig. 2).

Pero, ¿qué es esta escarola? Pues bien, a mi parecer, debemos pensar simplemente en hojas rizadas, «[...] largas, angostas y algo crespas»; quizá haya que asimilarlo a las guarniciones y adornos de vestidos, doblados y plegados a modo de hoja de lechuga. Por "escarolado", en el siglo XVIII, se entendía "[...] lo que está hecho y torcido como las escarolas: que también se dice Alechugado ${ }^{20}$. En todo caso, esta "idea" se correspondía, a la perfección, en los estilos de José Domínguez Bugarín y Domingo Rodríguez de Pazos, con cartuchos de hojas rizadas y de perfil aserrado, frente acanalado y adornado por cuentas y tachuelas, caracterizados por su naturalismo y movimiento —lo cual potencia el juego de luces y sombras-; lejos ya de los usos del siglo XVII.
Por otra parte, es cierto que la retablística gallega, hacia 1700, experimentó algunos "cambios" en su adorno que tuvieron que derivarse de la "interferencia" de un nuevo repertorio, probablemente venido del sur. Si bien aún no queda claro si el surgimiento de éste "nuevo repertorio" en Santiago de Compostela fue simplemente resultado de las «[...] libres negociaciones entre las fuerzas del mercado ${ }^{21}$; por lo tanto, una respuesta "espontánea": dado que nadie supo llenar el hueco dejado por Mateo de Prado; que cayó en desgracia el otro modelo de producción, esto es, el de las "compañías" de escultores y ensambladores, a favor de los entalladores; o bien reajustes en las tipologías para adaptarse a los "gustos" y la entrada en "vía muerta" de los usos artísticos de la segunda mitad del siglo XVIII2.

Poco después, el 7 de octubre de 1703, D. Juan de Sanmartín, canónigo de la Santa Apostólica y Metropolitana, ajustó con el Maestro de Fornelos, el retablo de Nuestra Señora de la Preñada para la Catedral. No obstante, este altar que se desmontó hacia 1849 —golpes de talla y relieves aún se conservan, a día de hoy, en el Museo de la Catedral-, se situó en un lugar aún sin determinar de la "nave de la Preñada": un espacio que mediaba, según García Iglesias, entre el Pórtico de la Gloria y el coro, cerca del trascoro ${ }^{23}$, pero diferente de éste, y de los altares de la Soledad y San Jorge ${ }^{24}$. Pues bien, el Cabildo decidió hacer un nuevo retablo para este espacio litúrgico por 1703, obrando ya en su poder «[...] una planta de dicho retablo [¿acaso de Domingo de Andrade?]»; en seguida se la entregó al escultor y entallador Rodríguez de Pazos, quien, por lo demás, se comprometió a ultimarlo para agosto de $1704^{25}$.

Este escultor inaugura el siglo XVIII [en Santiago de Compostela] con el barroco aportuguesado de que se resienten los escultores fronterizos. Sin embargo tallaba bien [dijo Couselo Bouzas respecto al Maestro de Fornelos] $]^{26}$

\section{¿"Otra" crisis de fin de siglo?}

Con todo, volvamos a Domingo de Andrade: el 24 de enero de 1700 el rector del Colegio 


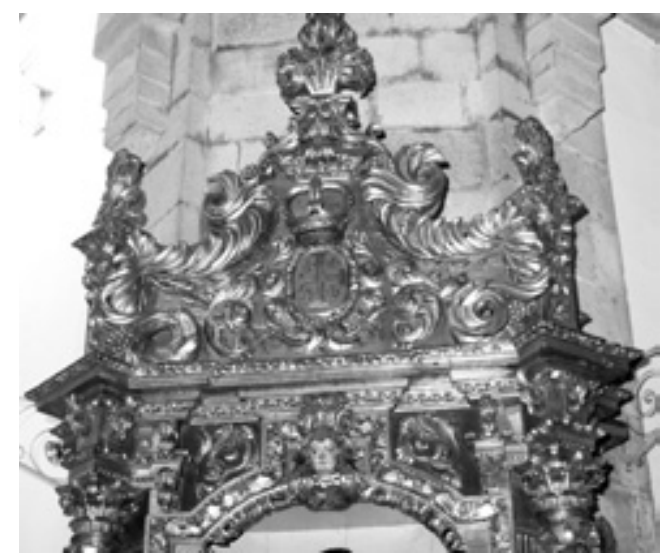

Fig. 3. ¿José y Ciprián Domínguez Bugarín?, retablo colateral de las clarisas, lado de la epístola, 1704 ca. Altar de S. Antonio de Padua, detalle del ático o copete.

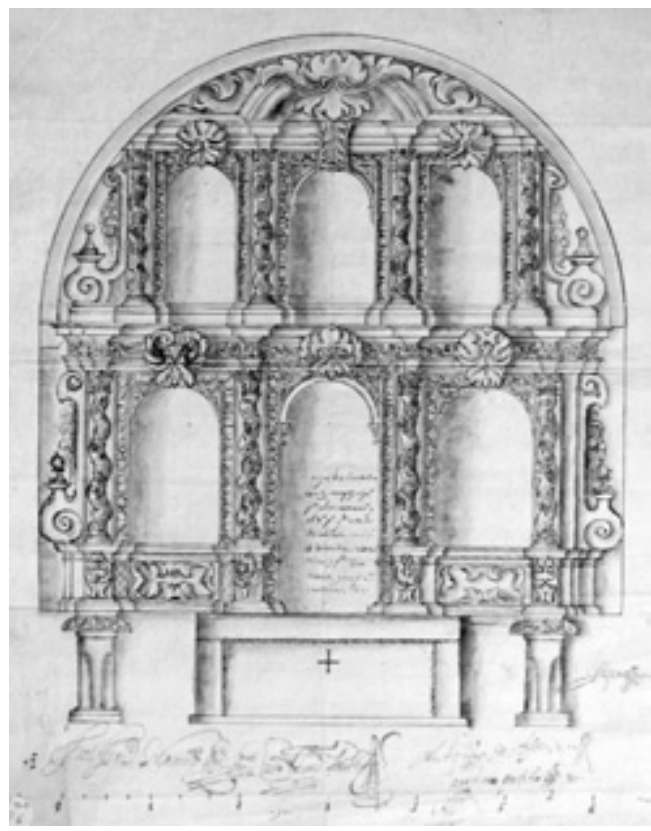

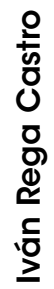

Fig. 4. ¿Domingo de Andrade?, trazas para el retablo mayor de San Lourenzo de Trasouto (Santiago de Compostela), ¿1700 ca.?, [vid. A. VIGO TRASANCOS (dir.), Planos y dibujos de arquitectura y urbanismo: Galicia en los siglos XVI y XVII, Santiago de Compostela, Consello Galego de Colexios de Aparelladores e Arquitectos Técnicos, 2003, Dib/185, ilust. 513 p.]

caso excepcional, se ha conservado adjunta a la escritura. En seguida, ésta se atribuyó al Maestro Mayor de la Catedral; dado que «[...] dieron por fiador a Domingo de Andrade» ${ }^{30}$. Según Taín Guzmán, el hecho de que sí sea suya la letra de la "nota" — «aquí ba custodia con 2 cuerpos [...]» (Fig. 4)— apoya su autoría ${ }^{31}$; con todo, hay que ser cautos: Folgar de la Calle, por ejemplo, subrayó lo retardatario de la tipología, por lo tanto, tal vez el dibujo fuese anterior a esta fecha.

Si por una parte, hay tipologías conservadoras y retardatarias, aún fieles a la ley de superposición de cuerpos, en contra de estructuras "subordinadas" y unitarias, y, por otra, un lenguaje aún por "codificar" en cuanto al adorno, sin lugar a dudas, esto agrandó la brecha que en el sistema del arte diferencia la estructura y 
la decoración. Así las cosas, hay que subrayar dos centros de interés en relación con los ensayos de Domingo de Andrade y las "soluciones" del retablo gallego en el cambio de siglo: a) en primer lugar, las "trazas", antes que ejemplos de un "diseño" de calidad, muy cuidado, eran simplemente la plasmación de un esquema de composición, donde los recursos del dibujo casi nunca alcanzaron a materializar la fantasía y riqueza de la decoración; con excepción de los tracistas y dibujantes mejor dotados. Entonces, a lo mejor esto se dio con mayor frecuencia de lo que creemos, en especial a fines del siglo XVIl; y para muestra, un botón: en la ciudad de Tui, el 2 de junio de 1694, la cofradía de Nuestra Señora de la Soledad ajustó con José Domínguez Bugarín y para su capilla de la Catedral, en el lado norte, el retablo de la Soledad; éste se comprometió a fabricarlo

[...] de la echura que contiene un bosquexo de planta que yzo el muy reberendo padre Fray Francisco Antonio de Andrade [hijo del "otro" Andrade, y, al parecer, adiestrado en el oficio de entallador junto a su padre ${ }^{32}$ ] Guardian de nuestro Padre S. Francisco desta ciudad y en virtu de dicha planta estar desnuda de talla ojamiento y guarnicion a de aumentar a ella toda la obra que toca guarnecer la arquitectura $[\ldots]^{33}$.

No cabe duda pues que la "revolución", ante todo, se relacionó con el adorno; b) en segundo lugar, hay que poner de relieve el gradual y muy lento abandono de una textura que gustaba de volúmenes "carnosos" y de la geometría, de 1689 a 1705 (aprox.), a la sombra de un lenguaje decorativo basado en lo vegetal, con ramilletes de frutas y laurel, cartelas "cactiformes", botones de acanto y florones. Cierto que su "canonización" se dio en el seno del obradoiro de la catedral de Santiago de Compostela, a lo largo de la segunda mitad del siglo $\mathrm{XVII}$, y, su difusión, merced al entorno artístico de Domingo de Andrade, en especial entre 1666-1677 (aprox.); también el "cambio" llegó de la mano del Maestro Mayor de la Catedral, circa 1700, y de un grupo de entalladores y ensambladores formados a su lado, codo con codo, desde fines del XVII: Jerónimo Patiño, Miguel de Romay, Ciprián Domínguez Bugarín...

Basta con echarle un ojo al adorno de los retablos colaterales de la iglesia de los jesuitas para hacerse una idea: ya antes incluso de la llegada de José Domínguez Bugarín a la Ciudad Santa y bajo los auspicios de Domingo de Andrade, el patrón de las tarjetas "canescas", duras y apergaminadas, de perfiles recortados, comenzó a "diluirse" a resultas de un gusto naturalista y "pictórico". Si el adorno del último tercio del siglo XVII se sujetaba a la forma cerrada y unitaria, éste otro, en cambio, hace desbordar los contornos y la forma se subyuga y casi desaparece por efecto de la luz y el "movimiento". Claro que falta por saber qué correspondía a la genialidad de Domingo de Andrade y qué al buen hacer de sus retableros. Sea como fuere, es muy tentadora la idea de atribuirle trazas y dibujos para retablística, antes de que Miguel de Romay se distinga como tracista y entallador. Huelga decir que desde 1676, en calidad de Maestro Mayor de la Catedral, era el único responsable no sólo por la dirección de las obras del Cabildo, sino también del trabajo de los maestros y oficiales; y de proyectar.

Si en verdad las trazas debían ajustarse a "códigos de representación" que no sabían reflejar esta nueva realidad del lenguaje —aún cuando son muy pocas las que nos han llegado- ${ }^{34}$, la obra de la iglesia de San Lourenzo de Trasouto, puesta en manos de los mismos arquitecto y ensambladores, a lo mejor fue menos retardataria de lo que dictó su planta. Habida cuenta que el «[...] retablo barroco evoluciona más por sus motivos [esto es, la decoración] que por su estructura [...]» $»^{35}$; éstos, se enfatizan y recargan, crecen y se plasman en un "adorno" que corroe más y más la estructura. Es más, en la Galicia del cambio de siglo, esta última "característica" está llamada a guiar buena parte de la producción de la primera mitad de XVIII. Siendo así, he aquí las claves en la evolución de la talla "escarolada": la obra de Antonio Afonsín y Ciprián Domínguez, justo por estos años de 1709-1712, se caracterizó por echar mano de tarjetas y volutas naturalistas y "pictóricas", con su frente engalanado con perlas ¿acaso "espinacas contadas"? -, acanalado, y, 


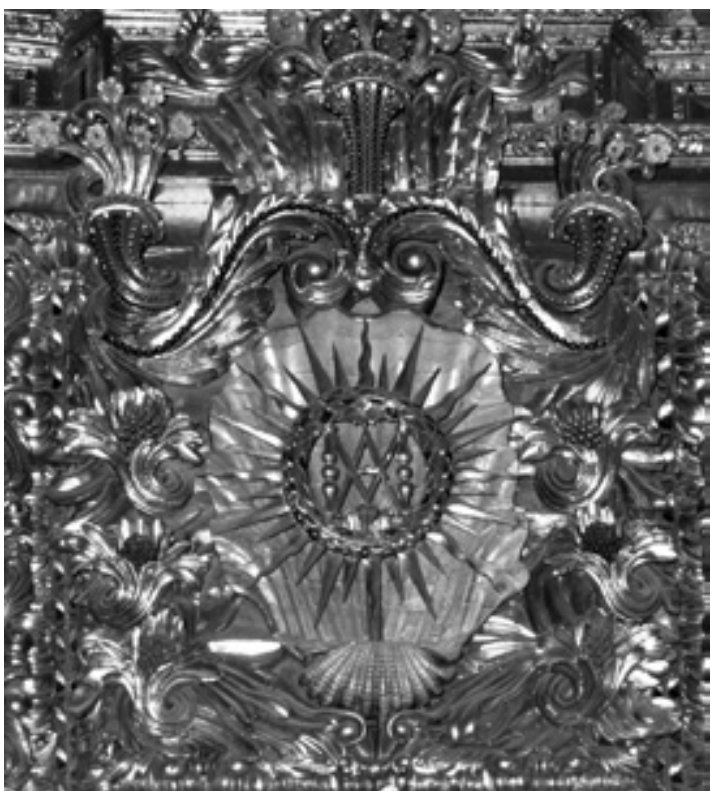

Fig. 5. Francisco de Castro Canseco, detalle del retablo colateral de la Inmaculada Concepción, monasterio de San Salvador de Celanova (Celanova, Ourense), 1714-1715.

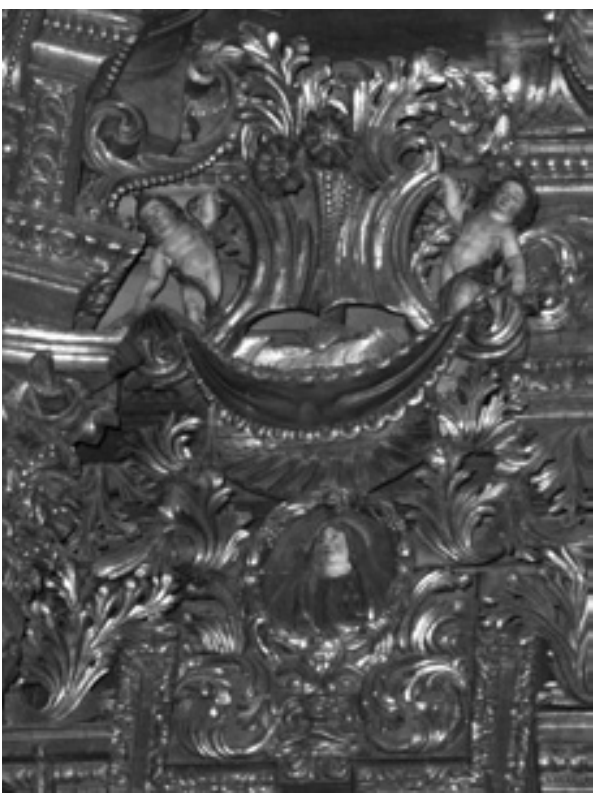

Fig. 6. Francisco de Castro Canseco, detalle del retablo mayor de San Paio de Antealtares (Santiago de Compostela), 1714-1715. a su vez, por dar un paso más en la evolución de la "escarola", hacia la "hoja de cardo" (Fig. 8), a base de lenguas dentadas y lobuladas; una marca de vanguardia atribuida erróneamente a Miguel de Romay.

Es curioso, según Taín Guzmán, éste figuró como carpintero y entallador en la Fábrica de la Catedral desde 169336; si bien, ya lo dejó claro Fernández Gasalla, su formación y su actividad artística, justamente por estos años — de 1693 a 1709-, era la de escultor, casi en exclusiva ${ }^{37}$. En cuanto a la retablística de Miguel de Romay, hay que mirar, sin duda, al maestro Afonsín y al obradoiro de la Catedral, donde trabajaron en régimen de compañía entre 1705-170838 (aprox.) - por ejemplo, en el retablo de Nuestra Señora de la Soledad, en su trascoro, entre 1704-1705; pagándoseles «[...] cinco mill ciento diez Reales [...] a Miguel de Romay, escultor, y a Antonio Alfonsín, entallador, por haver echo el retablo [...] de la Soledad [...]»—39; una organización del trabajo que seguramente no fue más allá de 1709. Si bien su "compañía" era algo anterior; dado que sus carreras se cruzaron, años antes (ca. 1700-1702), en la iglesia de San Vicente de Cespón (Boiro, A Coruña) ${ }^{40}$.

Aún sin negar la hipótesis de Otero Túñez, según la que el "amaestramiento" de Miguel de Romay en carpintería y retablística debió darse al lado de Domingo de Andrade, no cabe duda que sus enseñanzas le llegaron a través de Antonio Afonsín ${ }^{41}$.

\section{Hacer época}

[¿La historia del arte?]: se engendra en el combate entre aquellos que hicieron época y que luchan por seguir durando [...]; entre los dominantes [...] y los dominados, los nuevos que están entrando y que tienen todas las de ganar con la discontinuidad, la ruptura, la diferencia, la revolución [... $]^{42}$

P. Bourdieu, 1992 


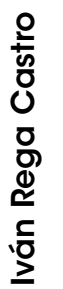

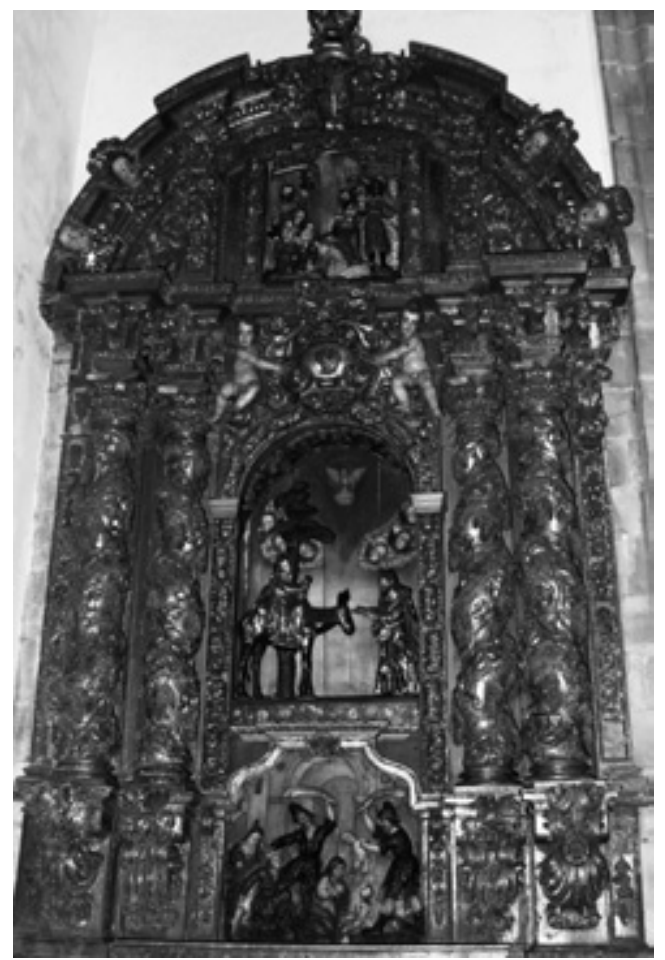

Fig. 7. ¿Miguel de Romay o Ciprián Domínguez Bugarín?, retablo colateral de la Cofradía de la Esclavitud, San Paio de Antealtares (Santiago de Compostela), antes de 1712.

En resumen, fue éste el "estilo aportuguesado" que cuajó en Santiago de Compostela por los años de 1700-1714 (aprox.); hay que diferenciar dos "recetas" que caracterizan su evolución y, por consiguiente, el estilo de algunos artífices: a) por una parte, una talla que grana y fructifica, a base de lenguas grandes, dentadas y rizadas, que poco a poco caminan hacia la hoja de cardo, de perfil lobulado y menos aserrado (Figs. 3 y 10); la cual crece en zarcillos, con "cogollos", y un tallo largo con una mazorca al extremo. Características, éstas, de la obra del viejo Afonsín, Ciprián Domínguez Bugarín, Ignacio Romero y Miguel de Romay, especialmente de éste último, al menos hasta 1717 o 1719; b) por otra, un adorno que crece y trepa, dando vueltas alrededor del elemento al que se adhiere, desplegando hojas de espada-

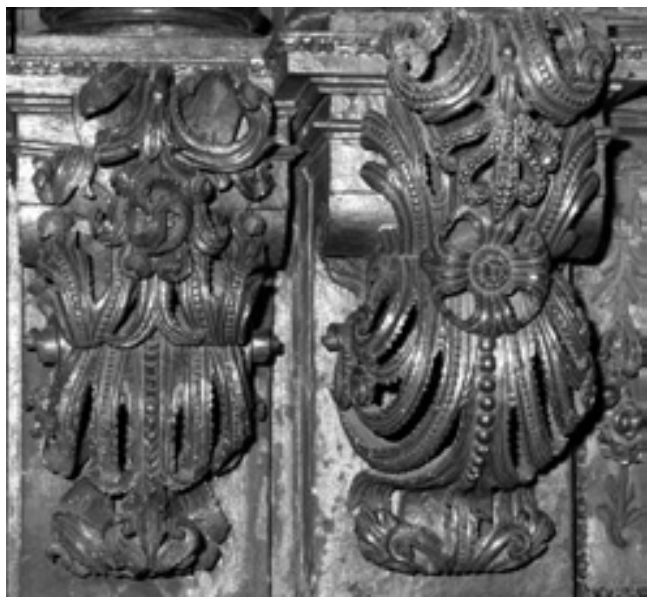

Fig. 8. ¿Miguel de Romay o Ciprián Domínguez Bugarín?, detalle de los netos y talla "escarolada".

ña, muy largas, frecuentemente de corte a bisel, y talla muy plana y recortada (Figs. 5 y 6 ). Éstas son las claves del estilo de Castro Canseco o Domingo Rodríguez de Pazos —asimismo de Jacinto de Barrios (fall. 1711)—, junto con la abundancia de cornucopias y ramilletes, granadas, flores y rosetas de numerosas coronas de pétalos y cálices tachonados.

Pues bien, en este "panorama" de obras y artistas a relacionar con la talla de escarola y un estilo aportuguesado, hay "otro" establecimiento de culto y oración que ocupa un lugar de privilegio, al lado del convento de las clarisas: la iglesia de las benedictinas de San Paio de Antealtares. En efecto, alrededor de 17101715, éstas tuvieron que afrontar el adorno de sus altares y hechura de tres de sus retablos principales (Fig. 7), comenzando por los retablos 


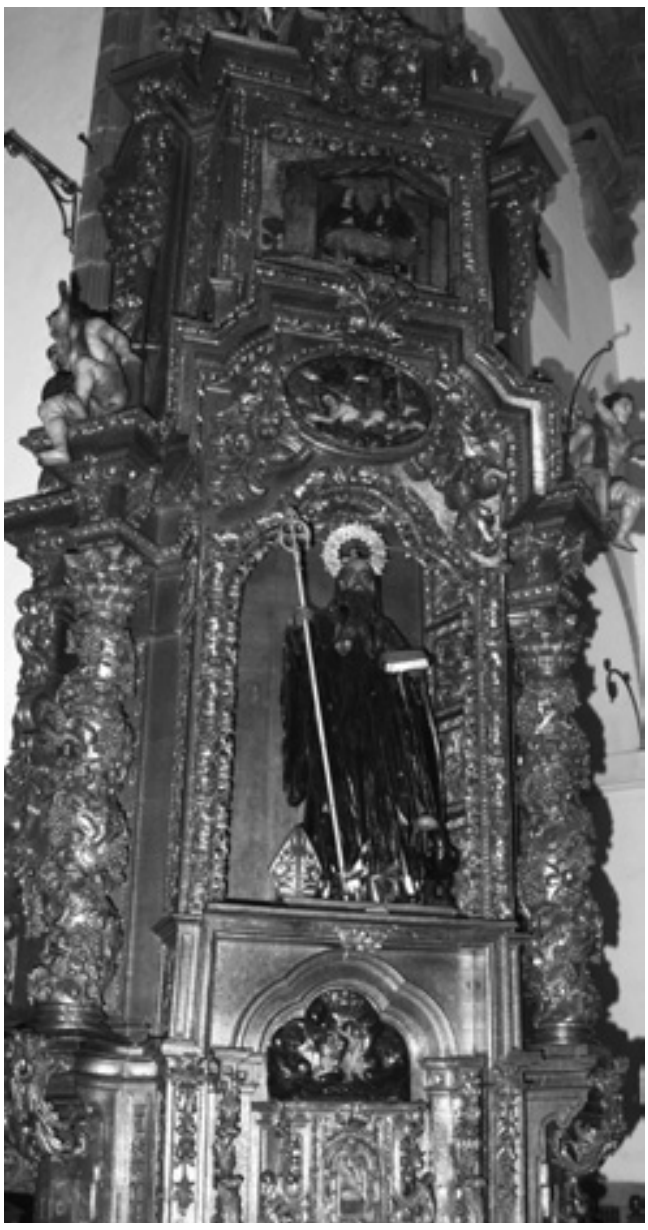

Fig. 9. ¿Ciprián Domínguez Bugarín y Antonio Afonsín?, retablo colateral del monasterio de San Paio de Antealtares (Santiago de Compostela), 1713-1714. Altar de S. Benito, lado de la epístola.
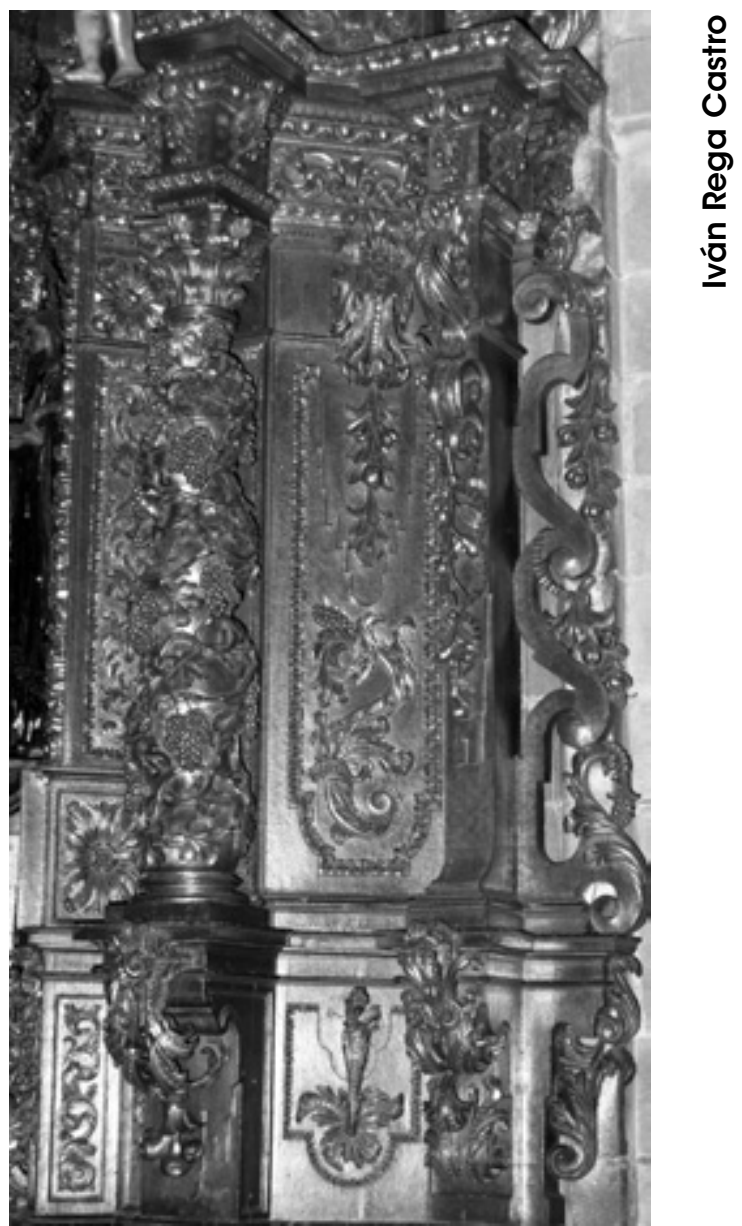

Fig. 10. ¿Ciprián Domínguez Bugarín y Antonio Afonsín?, detalle del costado. colaterales, justo en los machones del crucero hacia la capilla mayor; esto es, el altar de la Virgen del Rosario y el de S. Benito (Figs. 9 y 10) entre mayo de 1712 y 1713, Ciprián Domínguez se encargó (respectivamente) del altar del lado del evangelio y luego, entre octubre de 1713 y 1714, del retablo colateral de la epísto$\mathrm{la}^{43}$. En seguida, Francisco de Castro Canseco fue llamado a Santiago de Compostela por las pelayas para tallar y ensamblar el retablo mayor de su iglesia: el 10 de septiembre de 1714 hizo el contrato con las benedictinas de Antealtares y todo parece indicar que estuvo a su servicio hasta noviembre de 1716; además, éstas, conocedoras de que el "Maestro de Arquitectura" Castro Canseco estaba avecinado en Ourense, pusieron por condición que debía «[...] asentar el taller en esta ciudad [Santiago de Compostela] o su çircuyto sin que pueda dicho Maestro ponerle y fabricarle mas lexos de lo que ay de 


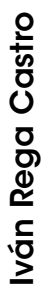
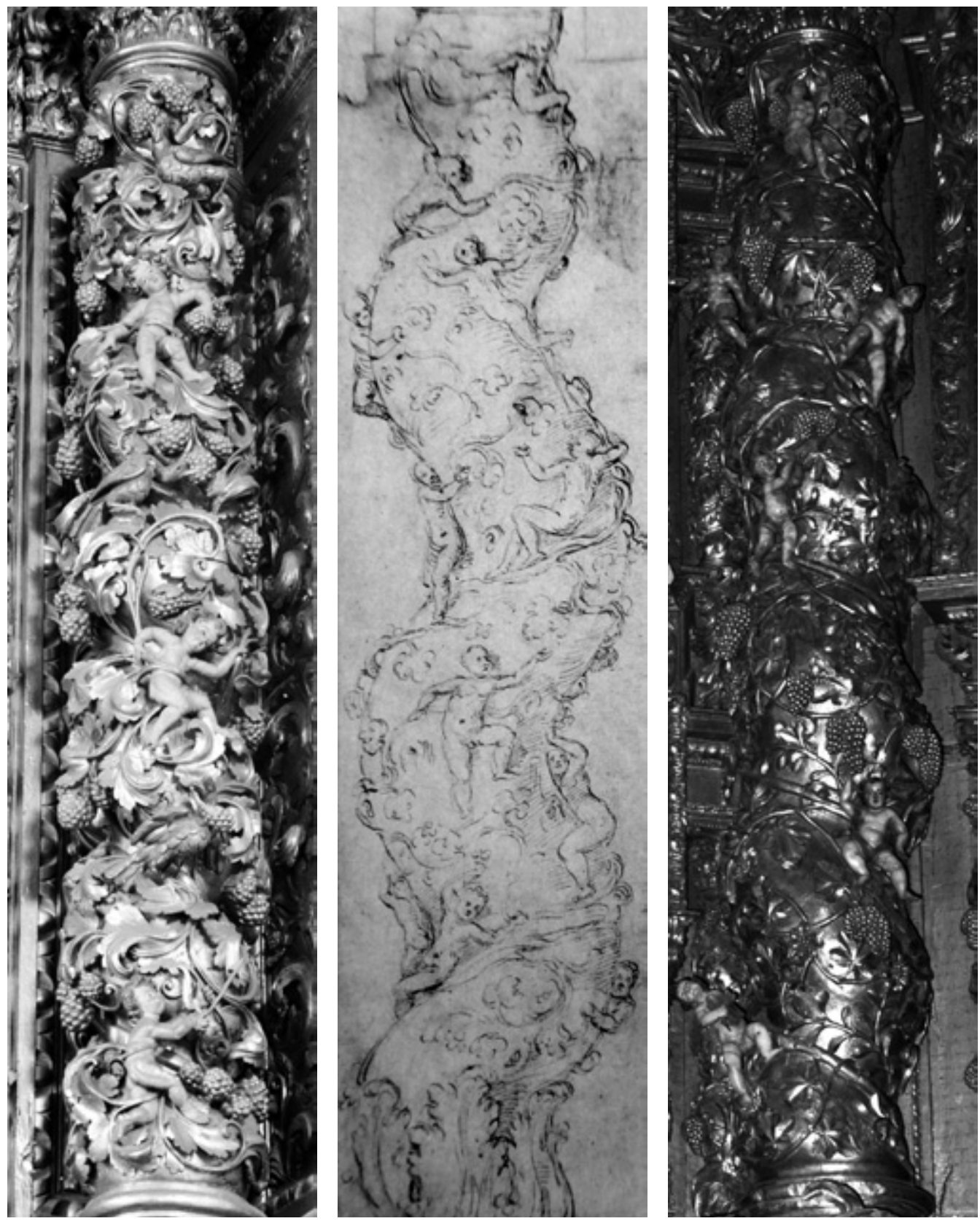

Fig. 11. (Izquierda) Bento da Costa, columna del retablo mayor de São Bento da Vitória do Porto (Oporto, Portugal), $1703-1705$.

Fig. 12. (Derecha) Francisco de Castro Canseco, columna del retablo mayor de San Paio de Antealtares (Santiago de Compostela), 1714-1715.

Fig. 13. (Centro) Giulio Romano, "Colonna tortile" (Oxford, Christ Church, inv. 0881, cat. 419 JBS 419), [vid. E. GOMBRICH, et al., Giulio Romano, Milano, Electra, 1989, ilust. 497 p.] 


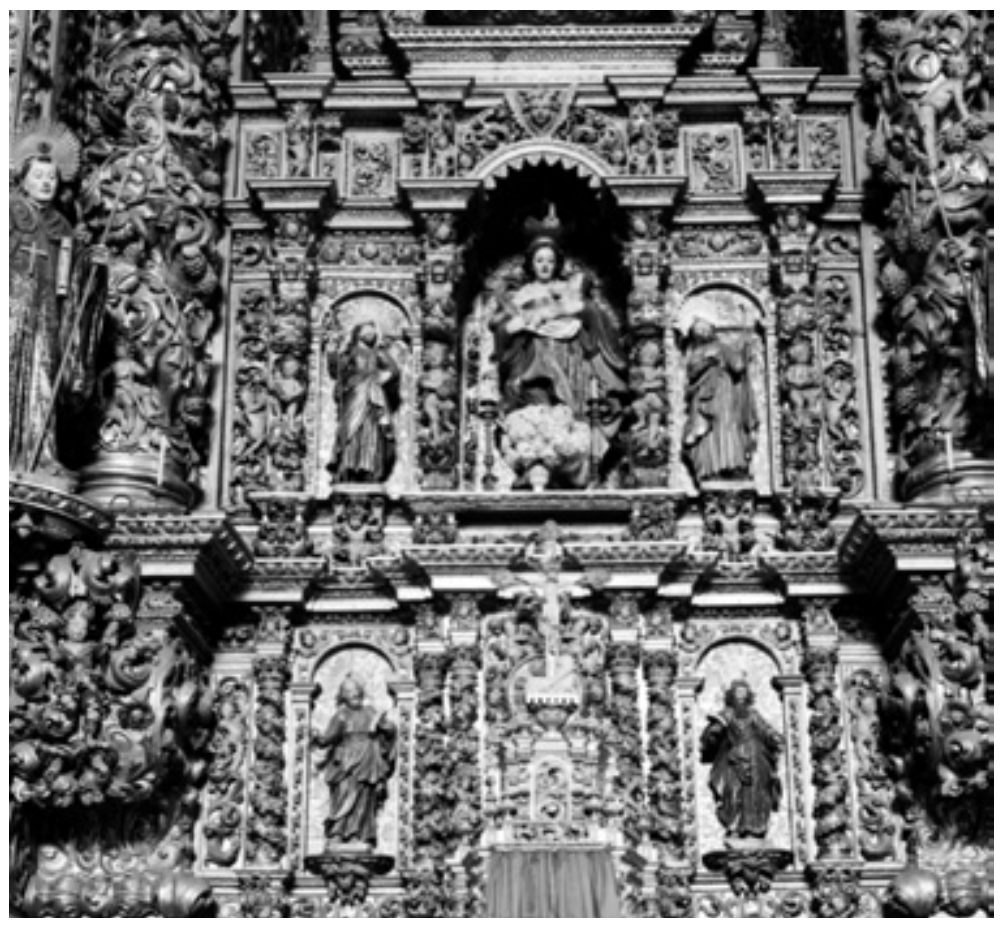

Fig. 14. Bento da Costa, cuerpo bajo del retablo mayor de São Bento da Vitória do Porto (Oporto, Portugal), 1703-1705 [vid. Colección fotográfica de Robert Ch. Smith "A talha em Portugal" (1960 ca.), Fundação Calouste Gulbenkian].

distancia desde esta Ciudad a la de puente ledezma [Ponte Ledesma, Vila de Cruces]». Esto significó que parte de su "escuela" se instalara por espacio de un par de años en la Ciudad del Apóstol, trabajando seguramente junto a mano de obra local; y, de esto, se derivó la implementación de soluciones y recetas ensayadas poco antes en la diócesis de Ourense. En cuanto al comportamiento del adorno, hay que poner de relieve el uso de columnas salomónicas engalanadas con pajarillos y amorcillos "vendimiadores" que se ocultan entre pámpanos y racimos de vid; y, de la misma forma, la proliferación de guirnaldas de margaritas y las hojas de espadaña (Figs. 11 y 13), o bien haces de plumas, que pueden ser señaladas/os como características de su modo de hacer.

Éstas se consideran influencias y préstamos llegados del norte de Portugal ${ }^{44}$.
Es bien sabido que encajan en las características del "estilo nacional", o por mejor decir, estilo português ${ }^{45}$, tal y como las formuló y fijó R. Smith. Es más, éstas están en relación con la escola do Porto, cuya producción se irradió por todo el noroeste — caso de la actividad artística de Manuel de Almeida (fl. 1706-1712), imaginero y entallador de Barcelos y el vale do Minho (Região do Norte)—_ ${ }^{46}$, hasta bien entrado el siglo XVIII; cuyo "paradigma" es el retablo mayor del monasterio de São Bento da Vitória do Porto (Porto, Região do Norte), entallado por Bento Alvarenga da Costa entre 1703-1705. En efecto, éste constituye uno de los primeros ejemplos en la región de Entre-Douro-e-Minho en aplicar las hojas de acanto alargadas y (progresivamente) desarmadas de sus perfiles aserrados, a modo de manojos de plumas (Fig. 14), en combinación con querubines, girasoles, amorcillos y cornucopias ${ }^{47}$. 


\section{A propósito de un "barroco aportuguesado"}

No obstante, incluso cuando una cultura trabaja con un repertorio amplio y multiforme, puede llegar a un punto muerto si se bloquean todas las opciones alternativas. Es entonces cuando se utilizan los repertorios adyacentes $[\ldots]^{48}$

I. Even-Zohar, 1999

Es justo decir que hay en la producción de Francisco de Castro Canseco y en los "recetarios" de los entalladores y retableros de la transición de XVII al XVIII, un lenguaje y un adorno novedosos y extraños a los usos artísticos de la Galicia atlántica, al menos hasta entonces. Don Francisco de Castro y Canseco (fall. 1724) era natural de Valderas (León), de ascendencia hidalga, y desempeñó oficios de maestro de obras, ensamblador y escultor ${ }^{49}$. Claro que buena parte de mi interés se concentra en su estilo, donde confluyeron justamente los dos ejes principales de penetración de información artística en el noroeste: uno este-oeste, con León y la diócesis de Astorga como "epicentro", y el otro norte-sur, hacia la región de EntreDouro-e-Minho; ya que, según Martín González $z^{50}$, su obra dio cuenta de una "orientación" que se liga a Portugal y, en especial, a Braga y Oporto. De hecho, dijo Folgar de la Calle: «No sería pues extraño que este artista de origen leonés [...] hubiese trabajado en algún conjunto retablístico del norte de Portugal $[\ldots] »^{51}$. Al respecto, López Vázquez creyó que éste empezó su andadura en el oficio de carpintero y entallador, seguramente formado en un taller con un radio de acción local, en la comarca de Tierra de Campos, y cercano a Valderas; donde tal vez «[...] llegaban los ecos de los principales núcleos artísticos castellano leoneses e incluso portugueses» ${ }^{52}$.

Entre las causas por las que es señalado como personificación de las "interferencias" entre Galicia y Portugal, se apunta, como se sabe, su participación en la talla de la capilla del Santo Cristo de la catedral de Ourense, entre 1696-1703, donde buscó la unificación y homogeneización de los espacios del camarín y su capilla ${ }^{53}$; esto, por medio de su revestimiento de madera y oro "a la portuguesa". Infelizmente, en la Catedral auriense no constaría, en esta ocasión, la participación de maestros de origen luso; no obstante, Folgar de la Calle apuntó esta hipótesis, que pone a oficiales de escultura portugueses a las órdenes de Francisco de Castro Canseco, entre los últimos años del siglo XVII y los primeros del $1700^{54}$. Entre medias, su área de influencia se amplía hasta Tui: estando en esta ciudad, el 6 de febrero de 1699, ajustó la sillería de coro de su Catedral, y, al parecer, en ésta trabajó de 1699 a $1700^{55}$;

[...] yo francisco de castro y canseco maestro de arquitectura vecino de la villa de mellide arsovispado de santiago me obligo hazer dicha obra [...], de dar feneiçida hacavada y asentada dentro de dos años [¿febrero de 1701 ? $]^{56}$.

Falta por saber si como creyó García Iglesias, la sillería pudo hacerse, al menos en parte, lejos de Tui; tal vez en Ourense. Esto es importante en la medida en que, de ser cierto, una eventual influencia de Francisco de Castro Canseco sobre José y Ciprián Domínguez Bugarín no resultaría "lógica". Con toda seguridad, estos dos no llegaron a verla ensamblada y asentada antes de marchar al norte, esto es, poco antes de julio del 1700; ya que la sillería no se montó hasta los inicios de 1701. Siendo así, su "contacto" no se dio hasta 1714 — ihasta su ida a Santiago?-

En todo caso, éstos y otros repertorios, en tanto que productos de lo colectivo, fueron aprehendidos, asimilados, reproducidos y (re)interpretados por los maestros gallegos. Siendo así, es justo decir que casi siempre resulta más provechoso para la historiografía del arte aislar sus reglas y materiales que buscar su "causa primera".

Sea como fuere, hay que poner de relieve que su llegada a Santiago de Compostela sí coincidió con la canonización en el sistema del arte de un "organismo" y adorno de tipo vegetal, que parece haber sustituido al acanto, de largas hojas a modo de "tralla de látigo" y trazado caligráfico; una suerte de hojas de espadaña que aparentaban gran maleabilidad para 
la hechura de complejos rizos, y que, de esta suerte, suscitó la aparición de la primeras huellas de una rudimentaria "dispersión de fuerzas" a través de la multiplicación de sus hojas en haces y ramilletes; éstas, se conjugaban con flores y granadas, en ocasiones, una mazorca al extremo, cornucopias, amorcillos, frutas y pajarillos picoteándolas. Por lo demás, no son pocos los que han venido a reconocerles, de un modo u otro, a estos motivos una función sígnica y un significado "trascendente"; si bien esto es ya harina de otro costal ${ }^{57}$.

\section{NOTAS}

\begin{abstract}
${ }^{1}$ Este trabajo de investigación se contextualiza en la actividad del grupo lacobus (GI-1907) de la Universidade de Santiago de Compostela (USC), en la que colaboro como investigador en formación y perfeccionamiento (IFP); y a su vez se incluye en el proyecto de investigación que dirige la Profa. A. Goy Diz (USC), «Artífices y patronos en el monacato gallego: futuro, presente y pasado» [Ref /Cód. INClTE09263-131PR], financiado por la Xunta de Galicia, Dirección Xeral de I+D+I. Éstos son, por otra parte, fragmentos de mi tesis doctoral, que recientemente defendí y me fue aprobada (22/09/2010), Los retablos mayores en el sur de la diócesis de Santiago de Compostela durante el siglo XVIII (1700-1775). Iglesia, cultura y poder, Santiago de Compostela, Servizo de Publicacións e Intercambio Científico, USC, 2011; dirigida por el Prof. Juan M. Monterroso Montero. En agradecimiento por su ayuda y orientación, esta breve nota.
\end{abstract}

${ }^{2}$ E. H. GOMBRICH, Arte e ilusión: estudio sobre la psicología de la representación pictórica, Barcelona, Gustavo Gili, 1979, 88 p.

${ }^{3}$ A. BONET CORREA, La arquitectura en Galicia durante el siglo XVII, Madrid, CSIC, 1984, 290 p. M. TAíN GUZMÁN, Domingo de Andrade, Maestro de obras de la catedral de Santiago (1639-1712), Sada, Do Cas- tro, 1998., 1, 359 p. J. J. MARTíN GONZÁLEZ, El Retablo barroco en España, Madrid, Alpuerto, 1993, 118 p.

${ }^{4}$ R. CACHEDA BARREIRO, "Domingo Rodríguez de Pazos", en A. PULIDO NOVOA (dir.), Artistas Galegos. Escultores. Séculos XVIII e XIX, Vigo, Nova Galicia, 2004, 148-179 p.

${ }^{5} \mathrm{~J}$. COUSELO BOUZAS, Galicia artística en el siglo XVIII y primer tercio del XIX (ed. facs.), Santiago de Compostela, Instituto Teológico Compostelano, 2005, 586 p.

${ }^{6}$ M. A. FERNÁNDEZ ÁlVAREZ Arte $y$ sociedad en Compostela, 16601710, A Coruña, Do Castro, 1996, $191 \mathrm{p}$.

${ }^{7}$ Prot. Andrés Moreda, 1735, leg. 3006, fol. 259 r., Santiago de Compostela, AHUS. Cit., A. FERNÁNDEZ GONZÁlEZ, Fernando de Casas y Novoa, arquitecto del Barroco diecochesCO, Madrid, Fundación Universitaria Española, 2006, 105 p.

${ }^{8}$ Prot. Matías López Fariña, 1734 , leg. (G) 1.311 (4), fols. 46 r, Archivo Histórico Provincial de Pontevedra (AHPP).

${ }^{9}$ J. M. LOTMAN Y B. A. USPENSKI, "Sobre el mecanismo semiótico de la cultura", en J. M. LOTMAN, La semiosfera III. Semiótica de las artes y de la cultura, Madrid, Cátedra, 1998, 187 p.

$10 \mathrm{~J}$. COUSELO BOUZAS, op. cit., 276 p. M. TAIÍN GUZMÁN, Domingo de Andrade..., op. cit., 1, 434-435 p.

11 J. M. LOTMAN, Cultura y ex- plosión: lo previsible y lo imprevisible en los procesos de cambio social, Barcelona, Gedisa, 1998, 182-184 p.

${ }^{12}$ M. TAÍN GUZMÁN, "Los escultores y entalladores de la villa de Pontevedra en el último tercio del siglo XVII", en Compostellanum, 3-4, 42, 1997, 389 y 392 p.

${ }^{13}$ M. C. FOLGAR DE LA CALLE, "El Retablo barroco gallego", en J. M. GARCÍA IGLESIAS (dir.), Galicia no tempo, Santiago de Compostela, Xunta de Galicia, 1992, 208 p. M. TAíN GUZMÁN, Domingo de Andrade..., op. cit., 1, $436 \mathrm{p}$.

${ }^{14} \mathrm{M}$. C. FOLGAR DE LA CALLE y J. M. LÓPEZ VÁZQUEZ, "La iglesia. LoS retablos", en J. M. GARCÍA IGLESIAS (dir.), Santiago. San Paio de Antealtares, Santiago de Compostela, Xunta de Galicia, Consellería de Cultura, Comunicación Social e Turismo, 1999, 278 p., nota a pié 49.

${ }^{15}$ M. C. FOLGAR DE LA CALLE, "El Convento de Santa Clara de Santiago", en M. E. GIGIREY LISTE (coord.), El Real Monasterio de Santa Clara de Santiago. Ocho siglos de claridad, 1193-1993, Santiago de Compostela, Real Convento de Santa Clara, Museo de Terra Santa, 1993, 126128 p. M. TAÍN GUZMÁN, Domingo de Andrade..., op. cit., 1, 67 p.

${ }^{16}$ L. FERNÁNDEZ GASALLA, "En torno a los orígenes de Miguel de Romay y a la escultura compostelana en el tránsito de los siglos XVII al XVIII", en Cuadernos de Estudios Gallegos, 
Instituto Padre Sarmiento de Estudios Gallegos, 53 (1996), 230 p.

17 M. A. FERNÁNDEZ ÁlVAREZ, op. cit., 190 p., vid. Apéndice: "Relación cronológica de contratos de obra", n. ${ }^{\circ} 145$

18 J. COUSELO BOUZAS, op. cit., 585-586 p

${ }^{19}$ R. CACHEDA BARREIRO, "Domingo Rodríguez de Pazos", op. cit., 150 p. J. M. LÓPEZ VÁZQUEZ, "Los Retablos mayores: homilía contrarreformista y propaganda monástica, en J. M. LÓPEZ VÁZQUEZ (coor.), Opus monasticorum: patrimonio, arte, historia y orden, Santiago de Compostela, Xunta de Galicia, 2005, 245 p.

${ }^{20}$ Diccionario de la lengua castellana en que se explica el verdadero sentido de las voces... / compuesto por la Real Academia Española ["Diccionario de Autoridades"], Madrid, Real Academia Española, Vda. de Francisco del Hierro 1732, 3, 559 p.

${ }^{21}$ I. EVEN-ZOHAR, "Planificación de la cultura y mercado", en M. IGLESIAS SANTOS (ed.), Teoría de los Polisistemas, Madrid, Arco, 1999, 76 p.

${ }^{22}$ L. FERNÁNDEZ GASALLA, "En torno a los orígenes de Miguel de Romay...", op. cit., 229-231 p.

23 J. M. GARCÍA IGLESIAS, A Catedral de Santiago e o Barroco, Santiago de Compostela, Colexio Oficial de Arquitectos de Galicia, 1990, 106 p.

${ }^{24}$ E. FERNÁNDEZ CASTIÑEIRAS, "El antiguo retablo de la capilla de Nuestra Señora de la Soledad en el trascoro de la catedral de Santiago", en Estudios sobre patrimonio artístico. Homenaje del Departamento de Historia del Arte... a la Profa. Dra. María del Socorro Ortega Romero, Santiago de Compostela, Servicio de publicacións, USC., 2002, 398-399, 401-402, 412 p.

$25 \mathrm{~J}$. COUSELO BOUZAS, op. cit., $586 \mathrm{p}$.

${ }^{26} \mathrm{~J}$. COUSELO BOUZAS, op. cit., $587 \mathrm{p}$.

${ }^{27}$ M. TAÍN GUZMÁN, Domingo de Andrade..., op. cit., 1, 65-66 p.

${ }^{28}$ R. OTERO TÚÑEZ, Legado artístico de la Compañía de Jesús a la Uni- versidad de Santiago de Compostela, Santiago de Compostela, Servicio de Publicacións, USC, 1986, 48-49 p. M. T. RÍOS MIRAMONTES, Aportaciones al Barroco Gallego. Un gran mecenazgo, Santiago de Compostela, Obradoiro de Encuadernaciones, 1980, 332-335 p. M. C. FOLGAR DE LA CALLE, "El Retablo barroco gallego", op. cit., 206 p. M. A. FERNÁNDEZ ÁlVAREZ, op. cit., vid. Apéndice: "Relación cronológica de contratos de obra", n. ${ }^{\circ} 137$.

${ }^{29}$ F. BOUZA BREY, "El desaparecido altar mayor barroco del monasterio de San Lorenzo de Trasouto", en Compostellanum, 12, 2 (1967), 337 p. R. OTERO TÚÑEZ, Legado artístico de la Compañía de Jesús..., op. cit., 48-50 p. J. M. GARCÍA IGLESIAS, El Barroco (II). Los arquitectos del siglo XVIII, otras actividades artísticas, A Coruña, Hércules, 1993, 14, 289-290 p.

${ }^{30} \mathrm{~F}$. BOUZA BREY, "El desaparecido altar mayor barroco del monasterio de San Lorenzo de Trasouto", op. cit., 337-340 p. M. C. FOLGAR DE LA CALLE, "El Retablo barroco gallego", op. cit., $206 \mathrm{p}$.

${ }^{31}$ M. TAÍN GUZMÁN, Domingo de Andrade..., op. cit., 1, 66 p.

${ }^{32}$ E. IGLESIAS ALMEIDA, Arte $y$ artistas en la antigua diócesis de Tui, Tui, Archivo y Museo Diocesano, 1989, 45 p. y M. TAíN GUZMÁN, Domingo de Andrade..., op. cit., 1, 64$65 \mathrm{p}$.

${ }^{33}$ D. ALVAREZ FERNÁNDEZ, El Retablo barroco en la antigua diócesis de Tui (Pontevedra), Pontevedra, Diputación de Pontevedra, 2001, 399-401 p.

${ }^{34} \mathrm{M}$. C. FOLGAR DE LA CALLE, "O estudo do retablo a través da documentación", en C. FONTENLA SANJUÁN (dir.), Os Profesionais da historia ante o Patrimonio Cultural, Santiago de Compostela, Xunta de Galicia, 1996, 183-187 p.

35 J. J. MARTÍN GONZÁLEZ, Escultura barroca castellana, Madrid, Publicaciones de la Fundación Lázaro Galdiano, 1959, $67 \mathrm{p}$.

${ }^{36}$ M. TAÍN GUZMÁN, Domingo de Andrade..., op. cit., 1, 66 p.
${ }^{37}$ L. FERNÁNDEZ GASALLA, "En torno a los orígenes de Miguel de Romay...", op. cit., 225-231 p.

${ }^{38}$ R. OTERO TÚÑEZ, "Miguel de Romay, retablista", en Compostellanum, 3, 2 (1958), 194-195 p. Cfr. J. M. GARCÍA IGLESIAS, A Catedral de Santiago e o Barroco, op. cit., 75-76 p. Ídem, El Barroco (II). Los arquitectos del siglo XVIII..., op. cit., 14, 342-343 p. M. TAÍN GUZMÁN, Domingo de Andrade..., op. cit., 1, 445 p.

39 J. COUSELO BOUZAS, op. cit., 592 p. J. M. GARCÍA IGLESIAS, A Catedral de Santiago e o Barroco, op. cit., 107 p. E. FERNÁNDEZ CASTIÑEIRAS, "El antiguo retablo de la capilla de Nuestra Señora de la Soledad...", op. cit., 397-398 p.

${ }^{40}$ M. I. PÉREZ PIÑEIRO, "Aportación documental al estudio históricoartístico del arciprestazgo de Ponte Beluso", en Cuadernos de estudios gallegos, 47, 113 (2000), 277-281 p.

${ }^{41}$ R. OTERO TÚÑEZ, "Miguel de Romay, retablista", op. cit., 197 p. M. C. FOLGAR DE LA CALLE, "Miguel de Romay", en Gran Enciclopedia gallega, Vitoria, Heraclio Fournier, 1974, $27,96 \mathrm{p}$.

${ }^{42}$ P. BOURDIEU, Las Reglas del arte: génesis y estructura del campo literario, Barcelona, Anagrama, 1995, 235 p. y ss.

43 J. COUSELO BOUZAS, op. cit., 201-202 y 275-276 p. M. A. FERNÁNDEZ ÁLVAREZ, op. cit., 177-178 p. M. C. FOLGAR DE LA CALLE y J. M. LÓPEZ VÁZQUEZ, "La iglesia. Los retablos", en J. M. GARCÍA IGLESIAS (dir.), Santiago. San Paio de Antealtares, op. cit. 134-145 p.

${ }^{44}$ M. C. FOLGAR DE LA CALLE, "La influencia portuguesa en los retablos barrocos de Galicia", en /l Congreso Internacional do Barroco, Maia, Universidad do Porto, 2003, 477-478 p.

45 N. M. FERREIRA-ALVES, "Talha", en J. FERNANDES PEREIRA (dir.)، Dicionário da arte Barroca em Portugal, Lisboa, Presença, 1989, 468 p.

${ }^{46} \mathrm{~V}$. SERRÃO, O Barroco, Lisboa, Presença, 2003, $102 \mathrm{p}$ 
${ }^{47}$ R. C. SMITH, A talha em Portugal, Lisboa, Livros Horizonte, 1962, 69-71 p. N. M. FERREIRA-ALVES, A Arte da talha no Porto na época barroca: artistas e clientela, materiais e técnica, Porto, Cámara Municipal, Arquivo Histórico, 1989, 1, 249 p. ĺdem, A escola de talha portuense e a sua influência no Norte de Portugal, Lisboa, Inapa, 2001, 48 p. J. J. B. FERREIRA-ALVES, "A nova capela-mor da igreja do mosteiro de São Bento da Vitória: Douro", en Estudos \& Documentos (Oporto), 2, 4 (1997), 215-220 p.

${ }^{48}$ I. EVEN-ZOHAR, "Factores y dependencias en la Cultura. Una Revisión de la Teoría de los Polisistemas", en M. IGLESIAS SANTOS (ed.), op. cit., 33-34 p.

${ }^{49}$ L. FERNANDEZ GASALLA, La Arquitectura en los tiempos de Domingo de Andrade: arquitectura y sociedad en Galicia (1660-1712), Santiago de Compostela, Servizo de Publicacións e Intercambio Científico, USC, 2004, 3, 1481 p.

50 J. J. MARTíN GONZÁLEZ, "El retablo en Portugal. Afinidades y diferencias con los de España", en As re- laçoes artísticas entre Portugal e Espanha na época dos Descobrimentos. II Simposio Luso-Espanhol de Historia da Arte, Coimbra, Universide de Coimbra, 1987, 2, 331-342 p.

${ }^{51}$ M. C. FOLGAR DE LA CALLE, "La influencia portuguesa en los retablos ...", op. cit., $478 \mathrm{p}$.

${ }^{52}$ M. C. FOLGAR DE LA CALLE y J. M. LÓPEZ VÁZQUEZ, "La iglesia. LoS retablos", en J. M. GARCÍA IGLESIAS (dir.), Santiago. San Paio de Antealtares, op. cit., 155 p. Cfr. L. FERNANDEZ GASALLA, La Arquitectura en los tiempos de Domingo de Andrade..., op. cit., 3, 1481-1483 p.

${ }^{53}$ C. CARAMÉS GONZÁleZ, "El escultor y entallador Francisco de Castro Canseco (1693-1724)", en Boletín Auriense, 2 (1972), 169-170 p. J. M. GARCÍA IGLESIAS, El Barroco (II). LoS arquitectos del siglo XVIII..., op. cit., 14, 268-271 p. L. FERNÁNDEZ GASALLA, "Francisco de Castro Canseco", en A. PULIDO NOVOA (dir.), Artistas Galegos. Escultores..., op. cit., 22 p. L. FERNANDEZ GASALLA, La Arquitectura en tiempos de Domingo de Andrade..., op. cit., 3, 1502- 1507 p.
${ }^{54}$ M. C. FOLGAR DE LA CALLE, "La influencia portuguesa en los retablos ...", op. cit., 478 p.

55 J. COUSELO BOUZAS, op. cit., 260 p. J. M. GARCÍA IGLESIAS, El Barroco(II). Los arquitectos del siglo XVIII..., op. cit., 14, 265 p. L. FERNANDEZ GASALLA, La Arquitectura en tiempos de Domingo de Andrade..., op. cit., 3, $1512 \mathrm{p}$.

${ }^{56}$ E. IGLESIAS ALMEIDA, Arte $y$ artistas en la antigua diócesis de Tui, op. cit., 39 p., vid. Documento n. ${ }^{\circ} 13$ (transcripción íntegra del documento), $153 \mathrm{p}$.

${ }^{57}$ En cuanto al "potencial" simbólico del adorno y en relación con el sistema del arte en Santiago de Compostela, entre 1695-1716 (aprox.), cabe citar a I. REGA CASTRO, "Entre España y Portugal. Las influencias del salomonismo sobre entalladores y ensambladores hacia 1700", en XVI Congreso Nacional de Historia del Arte. La Multiculturalidad en las Artes y en la Arquitectura, Las Palmas de Gran Canaria, 2006, 2, 419-426 p. A. VIGO TRASANCOS, "La invención de la arquitectura jacobea (1670-1712)", en Quintana, 5 (2006), 51-84 p. 